\title{
Association of different glucose traits with kidney function decline risk in a Chinese community- based population without chronic kidney disease
}

This article was published in the following Dove Press journal:

Therapeutics and Clinical Risk Management

\author{
Xingang Wang,' Fangfang \\ Fan, 'Jia Jia,' Xin Xu, ${ }^{2}$ \\ Xianhui Qin, ${ }^{2}$ Bo Zheng,' \\ Haixia Li, ${ }^{3}$ Liguang Dong, ${ }^{4}$ \\ Shuyu Wang, ${ }^{5}$ Jianping $\mathrm{Li},{ }^{\prime}$ \\ Yong Huo,' Jingtao Dou, ${ }^{6}$ \\ Yan Zhang'
}

'Department of Cardiology, Peking University First Hospital, Beijing, China;

${ }^{2}$ National Clinical Research Center for Kidney Disease, State Key Laboratory for Organ Failure Research, Renal Division, Nanfang Hospital, Southern Medical University, Guangzhou, China; ${ }^{3}$ Clinical Laboratory, Peking University First Hospital, Beijing, China; ${ }^{4}$ Peking University Shougang Hospital, Beijing, China; ${ }^{5}$ Beijing Hypertension League Institute, Beijing, China; ${ }^{6}$ Department of Endocrinology, Chinese PLA General Hospital, Beijing, China
Correspondence: Jingtao Dou Department of Endocrinology, Chinese PLA General Hospital, 28 Fuxing Road, Haidian District, Beijing 100853, China

Tel +86 I0 5549910 I

Fax +861068168631

Email jingtaodou@।63.com

Yan Zhang

Department of Cardiology, Peking

University First hospital, 8 Xishiku Street,

Xicheng District, Beijing 100034, China

Tel +86 1083575728

Fax +86 10 66137748

Email drzhyl 108@I63.com
Background: Chronic kidney disease (CKD) has become a major issue worldwide and hyperglycemia is known as an important risk factor responsible for CKD progression. Few studies have investigated whether fasting plasma glucose (FPG) could predict kidney function decline (KFD) risk better than postprandial plasma glucose, and vice versa. In this study, we investigated the roles of FPG and 2-hour plasma glucose (2 h-PG) in predicting KFD risk in a Chinese community-based population without baseline deterioration of kidney functions.

Methods: Subjects with normal kidney function from an atherosclerosis cohort in Beijing, China were followed up for 2.3 years. The outcome was KFD (a drop in glomerular filtration rate category accompanied by $25 \%$ or greater decline of estimated glomerular filtration rate from the baseline or a sustained decline of more than $5 \mathrm{~mL} / \mathrm{min} / 1.73 \mathrm{~m}^{2} /$ year rate).

Results: A total of 3,738 subjects were included of which, $7.7 \%$ of the subjects suffered from KFD. After covariates adjustments, both FPG $(\mathrm{OR}=1.23, P<0.001)$ and $2 \mathrm{~h}-\mathrm{PG}(\mathrm{OR}=1.07$, $P<0.001)$ were associated with KFD. Furthermore, FPG was independent of $2 \mathrm{~h}-\mathrm{PG}$ to predict $\mathrm{KFD}(\mathrm{OR}=1.26, P<0.001)$. Subgroup analyses and interaction tests including diabetes mellitus, after adjusting all covariates, revealed no significant heterogeneity among analyzed subgroups. We also found subjects with FPG level of $6.1-7.0 \mathrm{mmol} / \mathrm{L}$ and $>7.0 \mathrm{mmol} / \mathrm{L}$ had 1.83 times and 2.51 times KFD risk respectively, compared to subjects with FPG level $<5.6 \mathrm{mmol} / \mathrm{L}$.

Conclusion: FPG was superior to $2 \mathrm{~h}-\mathrm{PG}$ in predicting KFD in a Chinese community-based population without CKD. FPG screening may be an important measure for CKD primary prevention even in subjects with impaired fasting glucose.

Keywords: fasting plasma glucose, postprandial plasma glucose, kidney function decline, chronic kidney disease

\section{Introduction}

Chronic kidney disease (CKD) has become a major public health issue worldwide. A cross-sectional survey ${ }^{1}$ of a nationally representative sample of Chinese adults in 2010 showed that the overall prevalence of CKD was $10.8 \%$ in China and the estimated CKD patients reached about 119.5 million. However, only $12.5 \%$ of them were aware of the condition. Thus, identifying and treating related risk factors for early stages of CKD should be an effective approach to prevent and delay its progression. ${ }^{2}$

Hyperglycemia has been known as a key risk factor responsible for CKD progression. Several reviews emphasized that diabetes mellitus (DM) was mainly responsible for CKD in many developed and developing countries ${ }^{3,4}$ and also in China. ${ }^{5}$ Fasting plasma glucose (FPG) is an important index of hyperglycemia and considered a major risk factor for microvascular complications including CKD in patients with newly 
diagnosed type 2 diabetes. ${ }^{6}$ Postprandial blood glucose, in recent years, has been identified as a possible independent risk factor for cardiovascular disease (CVD). ${ }^{7,8}$ Nevertheless, whether FPG and postprandial plasma glucose play different roles in predicting CKD risk still remains unclear. In addition, few studies have investigated whether FPG can predict the risk of CKD progression better than postprandial plasma glucose and vice versa.

In the present study, our objective is to elucidate the roles of FPG and 2-hour plasma glucose (2 h-PG) in predicting CKD progression defined as kidney function decline (KFD) in a Chinese community-based population without baseline deterioration of kidney function.

\section{Research design and methods Data collection}

The subjects came from an atherosclerosis cohort in Gucheng and Pingguoyuan communities of Shijingshan district in Beijing, China. ${ }^{9}$ In brief, the baseline survey was conducted on 9,540 residents aged $\geq 40$ years from December 2011 to April 2012, and 5,962 of them with gene chip data were invited for a follow-up visit from May 2014 to July 2014. A total of 3,823 subjects responded onsite. There was no significant baseline characteristic difference between subjects who responded and those who did not (data not shown). We further excluded participants whose estimated glomerular filtration rate (eGFR) was below $60 \mathrm{~mL} / \mathrm{min} / 1.73 \mathrm{~m}^{2}$ and participants without creatinine, fasting blood glucose (FBG), and 2 h-PG data. Finally, a total of 3,738 eligible participants were included in this analysis. The flowchart is provided in Figure S1, and the STROBE statement checklist in Table S1. This study was approved by the ethics committee of Peking University and Peking University First Hospital. Each participant provided a written informed consent. We adhered to the principles of the Declaration of Helsinki and the procedures were performed in accordance with institutional guidelines.

Participant questionnaires were obtained and examinations conducted by trained research staffs according to a standard operating procedure. Their seated blood pressure was obtained using an Omron HEM-7117 electronic sphygmomanometer, and the average of three consecutive measurements was used in the analysis.

Blood samples were taken after an overnight fasting of at least 12 hours for the measurement of FPG, total cholesterol, triglycerides, and creatinine concentrations. After that, participants without history of diabetes took glucose powder (75 g) for oral glucose tolerance test (OGTT) while the others took steamed bread (100 g) instead for the measurement of 2 h-PG. All laboratory variables at baseline were measured on the Roche C8000 Automatic Analyzer.

Serum creatinine $(\mu \mathrm{mol} / \mathrm{L})$ at baseline was measured using the enzymatic method. Serum creatinine during revisit was measured using Jaffe's kinetic method on a Hitachi 7,180 Automatic Analyzer in the laboratory of Peking University First Hospital. Thus both, serum creatinine at baseline and revisit, were transformed into values measured by the enzymatic method. ${ }^{9}$ Then the value of eGFR was estimated using the equation derived from the CKD Epidemiology Collaboration. ${ }^{10}$

\section{Outcomes}

The primary outcome was KFD which was defined according to the Kidney Disease: Improving Global Outcome (KDIGO) 2012 definition $^{2}$ is as follows: a drop in the glomerular filtration rate category ( $\geq 90(\mathrm{G} 1), 60-89(\mathrm{G} 2)$, 45-59 (G3a), 30-44 (G3b), 15-29 (G4), and <15 (G5) $\mathrm{mL} / \mathrm{min} / 1.73 \mathrm{~m}^{2}$ ) accompanied by $25 \%$ or greater drop in eGFR from baseline or a sustained decline in eGFR of more than $5 \mathrm{~mL} / \mathrm{min} / 1.73 \mathrm{~m}^{2} /$ year.

\section{Definitions}

Current smoking was defined as smoking at least one cigarette per day for at least half a year. Current drinking was defined as drinking at least once per week for at least half a year. Body mass index (BMI) was calculated as weight (kilograms) divided by height (meters) squared. Hypertension was defined as any self-reported history of hypertension and/or systolic blood pressure $\geq 140 \mathrm{mmHg}$ and/or a diastolic blood pressure (DBP) $\geq 90 \mathrm{mmHg}$. DM was defined as any self-reported history of diabetes, or FPG $\geq 7.0 \mathrm{mmol} / \mathrm{L}$, or $2 \mathrm{~h}-\mathrm{PG}$ in OGTT $\geq 11.1 \mathrm{mmol} / \mathrm{L}$. CVD was defined as any self-reported history of coronary heart disease or stroke.

\section{Statistical analysis}

Data were expressed as mean \pm SD for continuous variables and percentages $(\%)$ for dichotomous variables. Normally distributed continuous variables were compared using independent $t$-test. Abnormally distributed continuous variables were expressed as median and interquartile range (IQR), and compared using Kruskal-Wallis Test. The Pearson chi-squared test was applied to all categorical variables.

Logistic regression models were used to investigate the effects of different glucose traits on the occurrence of outcomes. Covariates including age, sex, BMI, baseline 
eGFR, current smoking, current drinking, total cholesterol, triglyceride, hypertension, CVD history, antihypertensive drugs, hypoglycemic drugs, and lipid-lowering drugs were selected based on previous studies showing a relation to kidney functions. To investigate the different roles of FPG and $2 \mathrm{~h}$-PG in predicting KFD, they were put into the multiple regression models, first individually and then simultaneously. Furthermore, due to the strong correlation between FPG and $2 \mathrm{~h}-\mathrm{PG}$, we also compared the full regression model including both FPG and 2 h-PG with nested models with each of FPG and 2 h-PG.

Subgroup analysis examined the relationship between FPG and the risk of KFD according to age, sex, BMI, baseline eGFR, 2 h-PG, current smoking, current drinking, total cholesterol, triglyceride, hypertension, CVD, antihypertensive drugs, hypoglycemic drugs, and lipid-lowering drugs. Test for interaction in the logistic regression model was used to compare OR between the analyzed subgroups.

Moreover, the risk of microvascular complications associated with FPG indices was reported according to the glucose level. ${ }^{11}$ So participants were divided into four groups according to FPG: FPG $<5.6 \mathrm{mmol} / \mathrm{L}$; FPG 5.6-6.0 mmol/L; FPG 6.1-6.9 mmol/L; and FPG $\geq 7.0 \mathrm{mmol} / \mathrm{L}$. Multiple logistic regression models, adjusted for major confounding factors, were used to investigate the effects of different glucose groups on the occurrence of outcomes.
A $P$-value of $<0.05$ (two-sided) was considered statistically significant for all tests. All analyses were performed using Empower(R) (www.empowerstats.com; X\&Y Solutions, Inc., Boston, MA, USA) and R (http:/www.Rproject.org).

\section{Results}

A total of 3,738 subjects were included in the analysis. After a median 2.3-year (IQR: 2.28-2.39) follow-up, the incidence of KFD was $7.7 \%$ (289/3738). Baseline characteristics of all participants are shown according to the diabetes status (Table 1). The prevalence of DM at baseline was $23.9 \%$. Subjects with DM significantly differed from those without DM in most variables except DBP, total cholesterol, and current smoking status.

Table 2 displays the impact of FPG and/or 2 h-PG on outcomes. In Model-1, we put either FPG or $2 \mathrm{~h}-\mathrm{PG}$ in and adjust for other covariates. In Model-2, we further put FPG and $2 \mathrm{~h}-\mathrm{PG}$ into the same model, and adjust by variables in Model-1 plus 2 h-PG for FPG and vice versa.

The risk of KFD was associated with both FPG and $2 \mathrm{~h}-\mathrm{PG}$ in the crude model. In multiple logistic-regression analyses, every $1 \mathrm{mmol} / \mathrm{L}$ increase of FPG was associated with $23 \%$ risk of $\mathrm{KFD}(\mathrm{OR}=1.23,95 \% \mathrm{CI}$ : $1.16-1.31)$. However, 2 h-PG was only associated with $7 \%$ risk of KFD $(\mathrm{OR}=1.07,95 \% \mathrm{CI}: 1.04-1.11)$ on a scale of every $1 \mathrm{mmol} / \mathrm{L}$

Table I Baseline characteristics of all eligible participants

\begin{tabular}{|c|c|c|c|c|}
\hline Variable & Total & Non-DM & DM & P-value \\
\hline $\mathrm{N}$ & 3,738 & 2,844 & 894 & \\
\hline Age, years & $56.65 \pm 8.51$ & $55.66 \pm 8.13$ & $59.78 \pm 8.92$ & $<0.001$ \\
\hline Male, n (\%) & I,339 (35.80\%) & $941(33.10 \%)$ & $398(44.50 \%)$ & $<0.001$ \\
\hline BMI, kg/m² & $26.04 \pm 3.36$ & $25.85 \pm 3.36$ & $26.67 \pm 3.27$ & $<0.001$ \\
\hline SBP, mmHg & $133.25 \pm 16.45$ & $131.67 \pm 16.12$ & $138.29 \pm 16.48$ & $<0.001$ \\
\hline $\mathrm{DBP}, \mathrm{mmHg}$ & $75.01 \pm 9.72$ & $74.99 \pm 9.50$ & $75.08 \pm 10.40$ & 0.951 \\
\hline Total cholesterol, mmol/L & $5.32 \pm 1.00$ & $5.32 \pm 0.97$ & $5.30 \pm 1.11$ & 0.553 \\
\hline Triglycerides, mmol/L & $\mathrm{I} .30(0.92-\mathrm{I} .87)$ & $\mathrm{I} .26(0.90-\mathrm{I} .79)$ & $1.47(1.01-2.14)$ & $<0.001^{\mathrm{a}}$ \\
\hline $\mathrm{FPG}, \mathrm{mmol} / \mathrm{L}$ & $6.15 \pm 1.76$ & $5.5 I \pm 0.5 I$ & $8.18 \pm 2.59$ & $<0.001$ \\
\hline $2 \mathrm{~h}-\mathrm{PG}, \mathrm{mmol} / \mathrm{L}$ & $8.55 \pm 4.04$ & $6.83 \pm 1.67$ & $14.03 \pm 4.47$ & $<0.001$ \\
\hline Baseline eGFR, mL/min/I.73 $\mathrm{m}^{2}$ & $101.12 \pm 10.64$ & $101.71 \pm 10.32$ & $99.22 \pm 11.42$ & $<0.001$ \\
\hline Current smoking, n (\%) & 701 (I8.80\%) & $518(18.20 \%)$ & I $83(20.50 \%)$ & 0.132 \\
\hline Current drinking, n (\%) & $67(1.80 \%)$ & $43(1.50 \%)$ & $24(2.70 \%)$ & 0.021 \\
\hline Hypertension, n (\%) & I,8I 6 (48.60\%) & I,217 (42.80\%) & $599(67.00 \%)$ & $<0.001$ \\
\hline Cardiovascular disease, n (\%) & $47 \mid(12.60 \%)$ & $279(9.80 \%)$ & $192(21.50 \%)$ & $<0.001$ \\
\hline Hypoglycemic drugs, n (\%) & $381(10.20 \%)$ & $0(0.00 \%)$ & $381(43.10 \%)$ & $<0.001$ \\
\hline Antihypertensive drugs, n (\%) & I,I 75 (3I.60\%) & $747(26.40 \%)$ & $428(48.10 \%)$ & $<0.001$ \\
\hline Lipid-lowering drugs, n (\%) & 394 (10.60\%) & $236(8.40 \%)$ & I 58 (| $7.80 \%)$ & $<0.001$ \\
\hline
\end{tabular}

Notes: Normally distributed continuous variables were presented as mean \pm SD and compared using independent $t$-test. Abnormally distributed continuous variables were expressed as median and IQR, and acompared using Kruskal-Wallis Test.

Abbreviations: BMI, body mass index; DM, diabetes mellitus; DBP, diastolic blood pressure; eGFR, estimated glomerular filtration rate; FPG, fasting plasma glucose; $2 \mathrm{~h}-\mathrm{PG}$, 2-hour plasma glucose; SBP, systolic blood pressure; IQR, interquartile range. 
Table 2 Associations of different blood glucose traits and KFD according to DM status

\begin{tabular}{|c|c|c|c|c|c|c|}
\hline \multirow[t]{2}{*}{ KFD } & Crude model & \multirow[t]{2}{*}{$P$-value } & Model-I & \multirow[t]{2}{*}{$P$-value } & \multirow{2}{*}{$\begin{array}{l}\text { Model-2 } \\
\text { OR }(95 \% \mathrm{CI})\end{array}$} & \multirow[t]{2}{*}{$\overline{P \text {-value }}$} \\
\hline & OR $(95 \% \mathrm{Cl})$ & & OR $(95 \% \mathrm{Cl})$ & & & \\
\hline \multicolumn{7}{|l|}{ Total } \\
\hline $\mathrm{FPG}, \mathrm{mmol} / \mathrm{L}$ & $1.21(1.16,1.27)$ & $<0.001$ & $1.23(1.16,1.31)$ & $<0.001$ & $1.26(1.14,1.39)$ & $<0.001$ \\
\hline $2 \mathrm{~h}-\mathrm{PG}, \mathrm{mmol} / \mathrm{L}$ & $1.08(1.06,1.1 \mathrm{I})$ & $<0.001$ & $\mathrm{I} .07(\mathrm{I} .04, \mathrm{I} . \mathrm{II})$ & $<0.001$ & $0.99(0.94,1.03)$ & 0.562 \\
\hline \multicolumn{7}{|l|}{ Non-DM } \\
\hline $\mathrm{FPG}, \mathrm{mmol} / \mathrm{L}$ & I.4I (I.06, I.89) & 0.019 & $1.46(1.07,1.98)$ & 0.017 & $1.43(1.04,1.99)$ & 0.030 \\
\hline $2 \mathrm{~h}-\mathrm{PG}, \mathrm{mmol} / \mathrm{L}$ & $1.06(0.97,1.16)$ & 0.190 & $1.05(0.95,1.16)$ & 0.305 & $1.01(0.92,1.12)$ & 0.783 \\
\hline \multicolumn{7}{|l|}{ DM } \\
\hline $\mathrm{FPG}, \mathrm{mmol} / \mathrm{L}$ & $1.17(1.10,1.25)$ & $<0.001$ & $1.19(1.11,1.28)$ & $<0.001$ & $1.27(1.13,1.42)$ & $<0.001$ \\
\hline $2 \mathrm{~h}-\mathrm{PG}, \mathrm{mmol} / \mathrm{L}$ & $1.06(1.02,1.11)$ & 0.003 & $1.06(1.01,1.10)$ & 0.017 & $0.95(0.89,1.02)$ & 0.136 \\
\hline
\end{tabular}

Notes: Model-I: including either FPG or 2 h-PG, adjusted for age, sex, BMI, baseline eGFR, current smoking, current drinking, total cholesterol, triglyceride, hypertension, CVD history, antihypertensive drugs, hypoglycemic drugs, and lipid-lowering drugs. Model-2: including both the FPG and 2 h-PG, adjusted by variables in Model-I plus 2 h-PG for FPG and FPG for 2 h-PG, respectively.

Abbreviations: BMI, body mass index; CVD, cardiovascular disease; DM, diabetes mellitus; eGFR, estimated glomerular filtration rate; FPG, fasting plasma glucose; 2 h-PG, 2-hour plasma glucose; KFD, kidney function decline.

increase. Furthermore, when putting FPG and 2 h-PG into one model simultaneously, only the association of FPG and KFD (OR $=1.26,95 \%$ CI: $1.14-1.39)$ remained statistically significant.

Also, we found that the full model with FPG and 2 h-PG was significantly better than the model with 2 h-PG only $(P<0.001)$ but not better than the one with FPG only $(P=0.547)$.

Similar findings were observed in DM and non-DM group and there were no interactions between each glucose trait and diabetes status $(P$ for interaction $=0.403$ for FPG and $P$ for interaction $=0.335$ for $2 \mathrm{~h}-\mathrm{PG})$.

The relationships between KFD and different FPG level groups are shown in Table 3. Higher FPG level was associated with increased risk of KFD. Using the lowest $(<5.6 \mathrm{mmol} / \mathrm{L})$ FPG group as the control group, increased risk of KFD reached statistical significance at 1.83 times $(\mathrm{OR}=1.83$, 95\% CI: 1.27-2.65) in FPG level of 6.1-7.0 mmol/L group and 2.51 times $(\mathrm{OR}=2.51,95 \% \mathrm{CI}: 1.53-4.12)$ in FPG level of $>7.0 \mathrm{mmol} / \mathrm{L}$ group, respectively.

Subgroup analyses and interaction tests are presented in Figure 1. The trends for KFD were concordant in all subgroups stratified by each adjusted variable including sex (male or female), age ( $<60$ or $\geq 60$-year-old), BMI $(<28$ or $\geq 28 \mathrm{~kg} / \mathrm{m}^{2}$ ), baseline eGFR (grouped by median value), 2 h-PG $(<7.8$ or $\geq 7.8 \mathrm{mmol} / \mathrm{L})$, current smoking, current drinking, total cholesterol ( $<5.18$ or $\geq 5.18 \mathrm{mmol} / \mathrm{L})$, triglyceride ( $<1.70$ or $\geq 1.70 \mathrm{mmol} / \mathrm{L})$, hypertension, CVD, antihypertensive drugs, hypoglycemic drugs, and lipid-lowering drugs. Also, no significant interactions were observed between FBG and the modifying factors.

\section{Discussion}

The main findings of this cohort study are that FPG, independent of $2 \mathrm{~h}-\mathrm{PG}$, predicts the risk of KFD in a Chinese community-based population without CKD at baseline after 2.3-year follow-up. It is noteworthy that the risk of KFD has already significantly increased when baseline $\mathrm{FPG} \geq 6.1 \mathrm{mmol} / \mathrm{L}$.

CKD is becoming a global health burden for the general population, due to its epidemic size and constantly increasing prevalence and its potentially severe, life-threatening complications. Global deaths from kidney disease have risen by $83 \%$ since $1990 .{ }^{12}$ Hyperglycemia is known as a

Table 3 Associations of different FPG levels and KFD

\begin{tabular}{|c|c|c|c|c|c|}
\hline \multirow[t]{2}{*}{ KFD } & \multirow{2}{*}{$\begin{array}{l}\text { Incidence, } \\
\text { n (\%) }\end{array}$} & \multicolumn{2}{|l|}{ Crude analysis } & \multicolumn{2}{|c|}{ Multiple analysis ${ }^{\mathrm{a}}$} \\
\hline & & OR (95\% Cl) & $P$-value & OR (95\% Cl) & $P$-value \\
\hline \multicolumn{6}{|l|}{ FPG, $\mathrm{mmol} / \mathrm{L}$} \\
\hline$<5.6$ & $96(5.5)$ & I.0 (Ref) & & I.0 (Ref) & \\
\hline$\geq 5.6,<6.1$ & $48(6.0)$ & $1.09(0.76,1.56)$ & 0.627 & $1.02(0.7 \mathrm{I}, \mathrm{I} .48)$ & 0.897 \\
\hline$\geq 6.1,<7.0$ & $61(10.6)$ & $2.07(1.48,2.89)$ & $<0.001$ & $1.83(1.27,2.65)$ & 0.001 \\
\hline$\geq 7.0$ & $84(14.2)$ & $2.88(2.11,3.92)$ & $<0.001$ & $2.51(1.53,4.12)$ & $<0.001$ \\
\hline$P$ for trend & & & $<0.001$ & & $<0.001$ \\
\hline
\end{tabular}

Notes: ${ }^{2}$ Adjusted for age, sex, BMI, baseline eGFR, current smoking, current drinking, total cholesterol, triglyceride, hypertension, CVD history, antihypertensive drugs, hypoglycemic drugs, lipid-lowering drugs and 2 h-PG.

Abbreviations: 2 h-PG, 2-hour plasma glucose; BMI, body mass index; CVD, cardiovascular disease; eGFR, estimated glomerular filtration rate; FPG, fasting plasma glucose; KFD, kidney function decline. 


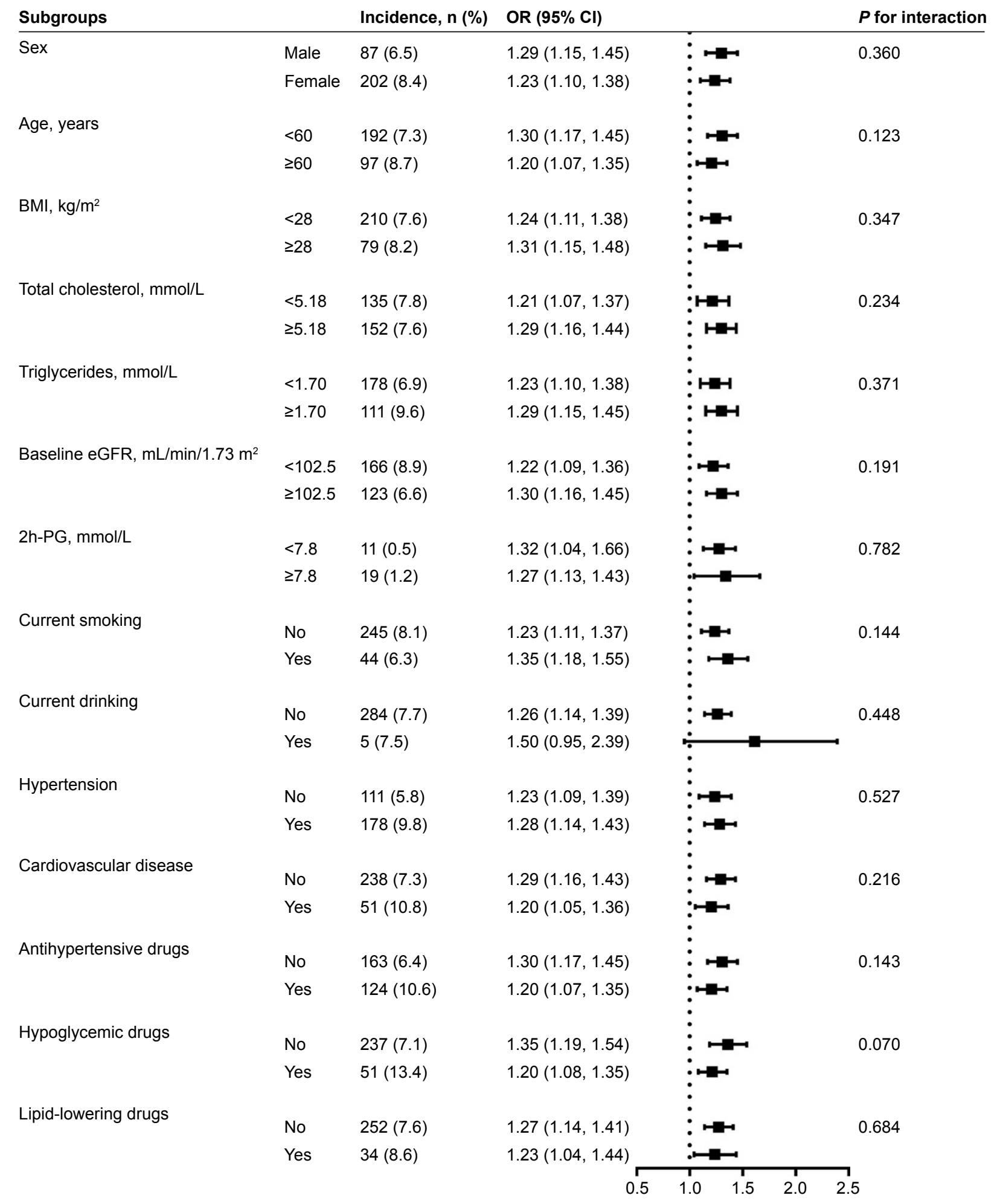

Figure I Subgroup analyses for the association between KFD and FPG level.

Note: Variables in the model: age, sex, BMI, baseline eGFR (grouped by median value), 2 h-PG, current smoking, current drinking, total cholesterol, triglyceride, hypertension, cardiovascular disease, antihypertensive drugs, hypoglycemic drugs, and lipid-lowering drugs.

Abbreviations: 2 h-PG, 2-hour plasma glucose; BMI, body mass index; eGFR, estimated glomerular filtration rate; KFD, kidney function decline; FPG, fasting plasma glucose.

very important factor in the deterioration of kidney function. Zhang et $\mathrm{al}^{5}$ found CKD was more commonly related to diabetes than to glomerulonephritis in both the general population and a hospitalized urban population in China.
Furthermore, both FPG and postprandial plasma glucose are commonly used parameters for evaluating glycemic status and were proven to be associated with CKD risk in previous studies. ${ }^{13}$ 
FPG was considered a risk factor for microvascular complications. The relationship between FPG and CKD, considered as one of the microvascular complications, had been reported in many cross-sectional designed studies. ${ }^{14-16}$ It was also suggested that increasing FPG level could be a major predictor for CKD progression. Iseki et al ${ }^{17}$ examined the relationship between FPG and end-stage renal disease (ESRD) in 78,529 screeners based on the results of community-based mass screening in Okinawa, Japan. During a 7.75-year follow-up period, a total of 133 subjects developed ESRD. The risk of ESRD development in the high-FPG group (defined as $126 \mathrm{mg} / \mathrm{dL}$ or more) was 3.098 times (95\% CI, $1.738-5.525 ; P<0.0001)$. Consistently, our study showed that high FPG levels independently increased the risk of KFD, which is used to evaluate CKD progression, in this community-based Chinese population without CKD at baseline.

On the other hand, postprandial plasma glucose was generally considered as an important risk factor for macrovascular complications. Postprandial plasma glucose was proven to be associated with CVD events not only in crosssectional studies ${ }^{8,18}$ but also in cohort studies. ${ }^{19}$ Meanwhile, postprandial plasma glucose was found to be related to CKD in an earlier study. ${ }^{20}$ In our study, we also found that $2 \mathrm{~h}-\mathrm{PG}$ was associated with KFD, one indicator for CKD progression, without adjusting FBG, which supported the speculation that postprandial plasma glucose may also play an important role in CKD.

In summary, FPG and postprandial plasma glucose were both shown to be risk factors for CKD when considered separately. However, to the best of our knowledge, few studies have investigated whether FPG could predict the risk of CKD better than $2 \mathrm{~h}-\mathrm{PG}$ and vice versa. In the study, we put FPG and $2 \mathrm{~h}-\mathrm{PG}$ into one multiple regression model simultaneously, and found that only the association of FPG and $\mathrm{KFD}(\mathrm{OR}=1.26,95 \% \mathrm{CI}: 1.14-1.39)$ remained statistically significant after adjusting 2 h-PG. Furthermore, due to the strong correlation between FPG and $2 \mathrm{~h}-\mathrm{PG}$, we also compared the full regression model including both FPG and 2 h-PG with nested models, with each of FPG and 2 h-PG, as repeated verification. For the first time, we reported that FPG was superior to $2 \mathrm{~h}-\mathrm{PG}$ in predicting the risk of KFD.

However, the precise mechanisms for the different roles of these two glucose traits in the progression of renal pathological changes are still unclear. Despite many studies concentrating on the structural changes seen in the glomerulus, abnormalities are also found in the tubulointerstitium. One explanation may be that FPG and postprandial plasma glucose may have different effects on interstitial fibrosis.
Ikee et $\mathrm{al}^{21}$ quantitatively evaluated pathological changes in the glomerulus, tubulointerstitium, and vessels in renal biopsy specimens from 23 patients with non-diabetic CKD. They demonstrated that FPG was significantly correlated with interstitial fibrosis $(r=0.532, P=0.009)$. Meanwhile, no statistically significant correlation was found between $2 \mathrm{~h} \mathrm{PG}$ and interstitial fibrosis $(r=0.081, P=0.71)$. In fact, tubulointerstitial changes have been reported to be quite significantly correlated with renal dysfunction and prognosis. ${ }^{22,23}$ This finding may partially explain why FPG is better in predicting KFD risk in our study.

Furthermore, our data revealed that the risk of KFD has already significantly increased when FPG $\geq 6.1 \mathrm{mmol} / \mathrm{L}$. Consistently, Nang et $\mathrm{al}^{11}$ have also found that the prevalence of CKD gradually increased in relation to higher FPG level, even beginning at level below the existing diagnostic threshold for DM of $7.0 \mathrm{mmol} / \mathrm{L}$. This association persisted after adjustment for age, gender, ethnic group, and hypertension. They also pointed out that lowering the cutoff point for the diagnosis of diabetes from 7.0 to $6.0 \mathrm{mmol} / \mathrm{L}$ may increase the sensitivity for detecting kidney complications such as albuminuria and/or eGFR $<60 \mathrm{~mL} / \mathrm{min} / 1.73 \mathrm{~m}^{2}$. In our study, the risk of KFD was also graded relative to FPG levels. Increasing KFD risk reached statistical significance from FPG level of $6.1 \mathrm{mmol} / \mathrm{L}$, which supports the idea of lowering the FPG threshold from 7.0 to $6.1 \mathrm{mmol} / \mathrm{L}$ may be appropriate for CKD primary prevention.

Our study had several limitations. First, there was no data of proteinuria at baseline in this cohort. According to KDIGO guidelines, some of the patients may have CKD if they have albuminuria, in this case especially those with DM. However, albuminuria index including albumin-creatinine ratio and urine protein measurement was not examined at baseline, so we could not exclude the possible influence of albuminuria in our analysis. Nevertheless, we mainly focused on the change of kidney function evaluated by eGFR in this study. Also, no significant heterogeneity was found in subgroup analysis according to diabetes, and the main result did not significantly change in the analysis of patients without DM and those with DM but not on hypoglycemic treatment. Second, only two time-points were examined. The slope of eGFR based on more time-point data would enhance the accuracy of kidney end point. However, similar methods using two time-points of creatinine measurements to determine the kidney end point can be found in previous studies. ${ }^{24,25}$ Third, it may bring questions when we put FPG and 2 h-PG into one model, as FPG and 2 h-PG are closely correlated. Nonetheless, we used likelihood ratio test to 
analysis the effects of different models, which consistently indicated FPG was a better predictor of KFD.

\section{Conclusion}

Our study demonstrates that FPG is independent and superior to $2 \mathrm{~h}-\mathrm{PG}$ in predicting the risk of KFD in a Chinese community-based population without CKD. FPG screening monitored conveniently and continuously, could be an important and convenient measurement for CKD primary prevention even in subjects with impaired fasting glucose.

\section{Acknowledgments}

The authors thank all the study team members for their participation. We especially thank the staff of Gucheng and Pingguoyuan Community Health Center for their support. This study was supported by a grant from the UMPUHSC joint institute for translational and clinical research (grant no BMU20160530 and BMU20110177).

\section{Disclosure}

The authors report no conflicts of interest in this work.

\section{References}

1. Zhang L, Wang F, Wang L, et al. Prevalence of chronic kidney disease in China: a cross-sectional survey. Lancet. 2012;379(9818):815-822.

2. National Kidney Foundation. K/DOQI clinical practice guidelines for chronic kidney disease: evaluation, classification, and stratification. Am J Kidney Dis. 2002;39(2 Suppl 1):S1-S266.

3. Jha V, Garcia-Garcia G, Iseki $\mathrm{K}$, et al. Chronic kidney disease: global dimension and perspectives. Lancet. 2013;382(9888):260-272.

4. Pyram R, Kansara A, Banerji MA, Loney-Hutchinson L. Chronic kidney disease and diabetes. Maturitas. 2012;71(2):94-103.

5. Zhang L, Long J, Jiang W, et al. Trends in chronic kidney disease in China. N Engl J Med. 2016;375(9):905-906.

6. Nazimek-Siewniak B, Moczulski D, Grzeszczak W. Risk of macrovascular and microvascular complications in type 2 diabetes: results of longitudinal study design. J Diabetes Complications. 2002;16(4):271-276.

7. Cavalot F, Petrelli A, Traversa M, et al. Postprandial blood glucose is a stronger predictor of cardiovascular events than fasting blood glucose in type 2 diabetes mellitus, particularly in women: lessons from the San Luigi Gonzaga Diabetes Study. J Clin Endocrinol Metab. 2006; 91(3):813-819.

8. Hanefeld M, Fischer S, Julius U, et al. Risk factors for myocardial infarction and death in newly detected NIDDM: the Diabetes Intervention Study, 11-year follow-up. Diabetologia. 1996;39(12):1577-1583.

9. Fan F, Qi L, Jia J, et al. Noninvasive Central Systolic Blood Pressure Is More Strongly Related to Kidney Function Decline Than Peripheral Systolic Blood Pressure in a Chinese Community-Based Population. Hypertension. 2016;67(6):1166-1172.
10. Levey AS, Stevens LA, Schmid CH, et al. A new equation to estimate glomerular filtration rate. Ann Intern Med. 2009;150(9):604-612.

11. Nang EE, Khoo CM, Tai ES, et al. Is there a clear threshold for fasting plasma glucose that differentiates between those with and without neuropathy and chronic kidney disease? The Singapore Prospective Study Program. Am J Epidemiol. 2009;169(12):1454-1462.

12. Lozano R, Naghavi M, Foreman K, et al. Global and regional mortality from 235 causes of death for 20 age groups in 1990 and 2010: a systematic analysis for the Global Burden of Disease Study 2010. Lancet. 2012;380(9859):2095-2128.

13. Gabir MM, Hanson RL, Dabelea D, et al. Plasma glucose and prediction of microvascular disease and mortality: evaluation of 1997 American Diabetes Association and 1999 World Health Organization criteria for diagnosis of diabetes. Diabetes Care. 2000;23(8):1113-1118.

14. Ohno M, Deguchi F, Izumi K, et al. Correlation between renal function and common risk factors for chronic kidney disease in a healthy middle-aged population: a prospective observational 2-year study. PLoS One. 2014;9(11):e113263.

15. Jessani S, Bux R, Jafar TH. Prevalence, determinants, and management of chronic kidney disease in Karachi, Pakistan - a community based cross-sectional study. BMC Nephrol. 2014;15:90.

16. Sun Y, Wang C, Yang W, et al. Fasting blood glucose, but not 2 -h postload blood glucose or $\mathrm{HbAlc}$, is associated with mild decline in estimated glomerular filtration rate in healthy Chinese. Int Urol Nephrol. 2015; 47(1):147-152.

17. Iseki K, Ikemiya Y, Kinjo K, Iseki C, Takishita S. Prevalence of high fasting plasma glucose and risk of developing end-stage renal disease in screened subjects in Okinawa, Japan. Clin Exp Nephrol. 2004;8(3): 250-256.

18. Yamasa T, Ikeda S, Koga S, et al. Evaluation of glucose tolerance, postprandial hyperglycemia and hyperinsulinemia influencing the incidence of coronary heart disease. Intern Med. 2007;46(9):543-546.

19. Cavalot F, Pagliarino A, Valle M, et al. Postprandial blood glucose predicts cardiovascular events and all-cause mortality in type 2 diabetes in a 14-year follow-up: lessons from the San Luigi Gonzaga Diabetes Study. Diabetes Care. 2011;34(10):2237-2243.

20. Chandra S, Singh AK, Singh M, et al. Prolonged elevated postprandial sugar augments severity in kidney disease: a north Indian hospital-based study. Ren Fail. 2014;36(1):50-54.

21. Ikee R, Hamasaki Y, Oka M, et al. Glucose metabolism, insulin resistance, and renal pathology in non-diabetic chronic kidney disease. Nephron Clin Pract. 2008;108(2):C163-C168.

22. Nangaku M. Mechanisms of tubulointerstitial injury in the kidney: final common pathways to end-stage renal failure. Intern Med. 2004; 43(1):9-17.

23. Kang DH, Kanellis J, Hugo C, et al. Role of the microvascular endothelium in progressive renal disease. J Am Soc Nephrol. 2002;13(3): 806-816.

24. Madero M, Peralta C, Katz R, et al. Association of arterial rigidity with incident kidney disease and kidney function decline: the Health $\mathrm{ABC}$ study. Clin J Am Soc Nephrol. 2013;8(3):424-433.

25. Li Y, Xie D, Qin X, et al. Metabolic syndrome, but not insulin resistance, is associated with an increased risk of renal function decline. Clin Nutr. 2015;34(2):269-275. 


\section{Supplementary materials}

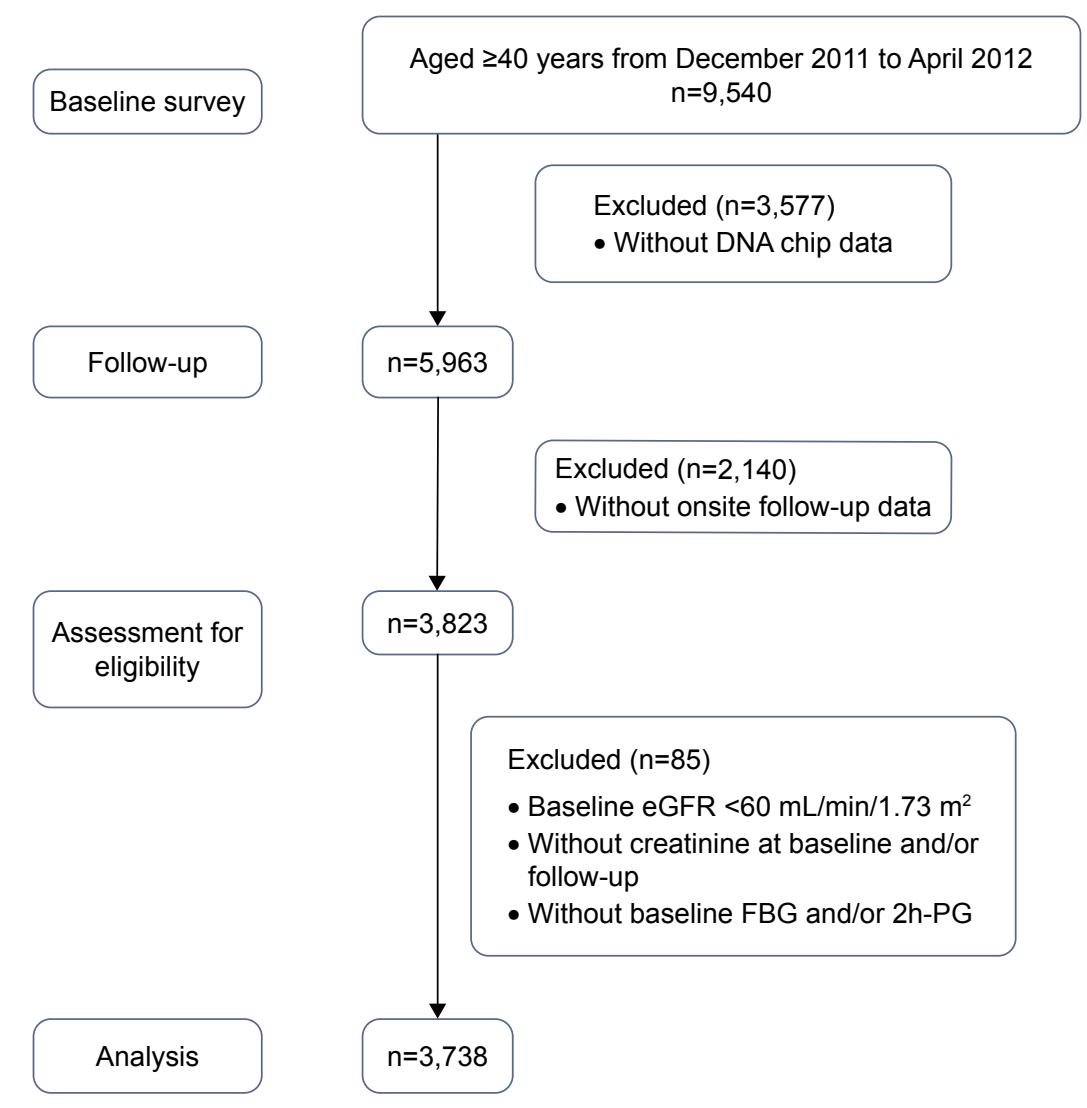

Figure SI CONSORT flow diagram.

Abbreviations: 2 h-PG, 2-hour plasma glucose; eGFR, estimated glomerular filtration rate; FBG, fasting blood glucose.

Table SI STROBE Statement-checklist of items that should be included in reports of observational studies

\begin{tabular}{|c|c|c|c|c|}
\hline & $\begin{array}{l}\text { Item } \\
\text { no }\end{array}$ & Recommendation & $\begin{array}{l}\text { Page } \\
\text { no }\end{array}$ & $\begin{array}{l}\text { Relevant } \\
\text { text from } \\
\text { manuscript }\end{array}$ \\
\hline \multirow[t]{2}{*}{ Title and abstract } & I & a) Indicate the study's design with a commonly used term in the title or the abstract & I & $\mathrm{I}-2$ \\
\hline & & $\begin{array}{l}\text { b) Provide in the abstract an informative and balanced summary of what was done and what } \\
\text { was found }\end{array}$ & 2 & $35-48$ \\
\hline \multicolumn{5}{|l|}{ Introduction } \\
\hline Background/rationale & 2 & Explain the scientific background and rationale for the investigation being reported & 3 & $55-70$ \\
\hline Objectives & 3 & State specific objectives, including any pre-specified hypotheses & 3 & $7 \mid-73$ \\
\hline \multicolumn{5}{|l|}{ Methods } \\
\hline Study design & 4 & Present key elements of study design early in the paper & 3 & 76 \\
\hline Setting & 5 & $\begin{array}{l}\text { Describe the setting, locations, and relevant dates, including periods of recruitment, exposure, } \\
\text { follow-up, and data collection }\end{array}$ & $3-4$ & $76-80$ \\
\hline Participants & 6 & $\begin{array}{l}\text { a) Cohort study - Give the eligibility criteria and the sources and methods of selection of } \\
\text { participants. Describe methods of follow-up } \\
\text { Case-control study - Give the eligibility criteria, the sources and methods of case ascertainment, } \\
\text { and control selection. Give the rationale for the choice of cases and controls } \\
\text { Cross-sectional study - Give the eligibility criteria and the sources and methods of selection of } \\
\text { participants } \\
\text { b) Cohort study - For matched studies, give matching criteria and number of exposed and } \\
\text { unexposed } \\
\text { Case-control study - For matched studies, give matching criteria and the number of controls } \\
\text { per case }\end{array}$ & $3-4$ & $76-85$ \\
\hline
\end{tabular}


Table SI (Continued)

\begin{tabular}{|c|c|c|c|c|}
\hline & $\begin{array}{l}\text { Item } \\
\text { no }\end{array}$ & Recommendation & $\begin{array}{l}\text { Page } \\
\text { no }\end{array}$ & $\begin{array}{l}\text { Relevant } \\
\text { text from } \\
\text { manuscript }\end{array}$ \\
\hline Variables & 7 & $\begin{array}{l}\text { Clearly define all outcomes, exposures, predictors, potential confounders, and effect modifiers. } \\
\text { Give diagnostic criteria, if applicable }\end{array}$ & $3-5$ & $76-119$ \\
\hline $\begin{array}{l}\text { Data sources/ } \\
\text { measurement }\end{array}$ & $8^{a}$ & $\begin{array}{l}\text { For each variable of interest, give sources of data and details of methods of assessment } \\
\text { (measurement). Describe comparability of assessment methods if there is more than one group }\end{array}$ & $3-4$ & $76-104$ \\
\hline Bias & 9 & Describe any efforts to address potential sources of bias & 5 & $121-139$ \\
\hline Study size & 10 & Explain how the study size was arrived at & & \\
\hline $\begin{array}{l}\text { Quantitative } \\
\text { variables }\end{array}$ & II & $\begin{array}{l}\text { Explain how quantitative variables were handled in the analyses. If applicable, describe which } \\
\text { groupings were chosen and why }\end{array}$ & 5 & $121-139$ \\
\hline \multirow[t]{2}{*}{ Statistical methods } & 12 & $\begin{array}{l}\text { a) Describe all statistical methods, including those used to control for confounding } \\
\text { b) Describe any methods used to examine subgroups and interactions } \\
\text { c) Explain how missing data were addressed } \\
\text { d) Cohort study - If applicable, explain how loss to follow-up was addressed } \\
\text { Case-control study - If applicable, explain how matching of cases and controls was addressed } \\
\text { Cross-sectional study - If applicable, describe analytical methods taking account of sampling } \\
\text { strategy }\end{array}$ & $\begin{array}{l}5 \\
5 \\
3 \\
3\end{array}$ & $\begin{array}{l}121-144 \\
135-139 \\
80-81 \\
77-80\end{array}$ \\
\hline & & e) Describe any sensitivity analyses & 6 & $164-165$ \\
\hline \multicolumn{5}{|l|}{ Results } \\
\hline Participants & $13^{\mathrm{a}}$ & $\begin{array}{l}\text { a) Report numbers of individuals at each stage of study - eg, numbers potentially eligible, } \\
\text { examined for eligibility, confirmed eligible, included in the study, completing follow-up, and } \\
\text { analyzed } \\
\text { b) Give reasons for non-participation at each stage } \\
\text { c) Consider use of a flow diagram }\end{array}$ & $3-4$ & $76-84$ \\
\hline \multirow[t]{3}{*}{ Descriptive data } & $14^{\mathrm{a}}$ & $\begin{array}{l}\text { a) Give characteristics of study participants (eg, demographic, clinical, social), information on } \\
\text { exposures, and potential confounders }\end{array}$ & 6 & $149-153$ \\
\hline & & b) Indicate number of participants with missing data for each variable of interest & $3-4$ & 78-84 \\
\hline & & c) Cohort study - Summarize follow-up time (eg, average and total amount) & 6 & $149-150$ \\
\hline Outcome data & $15^{\mathrm{a}}$ & $\begin{array}{l}\text { Cohort study - Report numbers of outcome events or summary measures over time } \\
\text { Case-control study - Report numbers in each exposure category, or summary measures of } \\
\text { exposure } \\
\text { Cross-sectional study - Report numbers of outcome events or summary measures }\end{array}$ & 6 & $150-152$ \\
\hline \multirow[t]{2}{*}{ Main results } & 16 & $\begin{array}{l}\text { a) Give unadjusted estimates and, if applicable, confounder-adjusted estimates and their } \\
\text { precision }(\mathrm{eg}, 95 \% \mathrm{Cl}) \text {. Make clear which confounders were adjusted for and why they were } \\
\text { included }\end{array}$ & 6 & $154-168$ \\
\hline & & $\begin{array}{l}\text { b) Report category boundaries when continuous variables were categorized } \\
\text { c) If relevant, consider translating estimates of relative risk into absolute risk for a meaningful } \\
\text { time period }\end{array}$ & 6 & $|50-| 5 \mid$ \\
\hline Other analyses & 17 & Report other analyses done - eg, analyses of subgroups and interactions and sensitivity analyses & $6-7$ & $166-180$ \\
\hline \multicolumn{5}{|c|}{ r } \\
\hline Key results & 18 & Summarize key results with reference to study objectives & 7 & $182-185$ \\
\hline Limitations & 19 & $\begin{array}{l}\text { Discuss limitations of the study, taking into account sources of potential bias or imprecision. } \\
\text { Discuss both direction and magnitude of any potential bias }\end{array}$ & 9 & $245-260$ \\
\hline Interpretation & 20 & $\begin{array}{l}\text { Give a cautious overall interpretation of results considering objectives, limitations, multiplicity } \\
\text { of analyses, results from similar studies, and other relevant evidence }\end{array}$ & $7-9$ & $186-260$ \\
\hline Generalizability & 21 & Discuss the generalizability (external validity) of the study results & 9 & $242-244$ \\
\hline \multicolumn{5}{|l|}{ Other information } \\
\hline Funding & 22 & $\begin{array}{l}\text { Give the source of funding and the role of the funders for the present study and, if applicable, } \\
\text { for the original study on which the present article is based }\end{array}$ & 10 & $270-272$ \\
\hline
\end{tabular}

Notes: a Gives information separately for cases and controls in case-control studies and, if applicable, for exposed and unexposed groups in cohort and cross-sectional studies. An explanation and elaboration article discusses each checklist item and gives a methodological background and published examples of transparent reporting. The STROBE checklist is best used in conjunction with this article (freely available on the Websites of PLoS Medicine at http://www.plosmedicine.org/, Annals of Internal Medicine at http://www.annals.org/, and Epidemiology at http://www.epidem.com/). Information on the STROBE Initiative is available at www.strobe-statement.org. 


\section{Publish your work in this journal}

Therapeutics and Clinical Risk Management is an international, peerreviewed journal of clinical therapeutics and risk management, focusing on concise rapid reporting of clinical studies in all therapeutic areas, outcomes, safety, and programs for the effective, safe, and sustained use of medicines. This journal is indexed on PubMed Central, CAS,

EMBase, Scopus and the Elsevier Bibliographic databases. The manuscript management system is completely online and includes a very quick and fair peer-review system, which is all easy to use. Visit $\mathrm{http}: / / \mathrm{www}$.dovepress.com/testimonials.php to read real quotes from published authors.

Submit your manuscript here: http://www.dovepress.com/therapeutics-and-clinical-risk-management-journal 